Nigerian Journal of Technology (NIJOTECH)

Vol. 38, No. 4, October 2019, pp.997 - 1002

Copyright@ Faculty of Engineering, University of Nigeria, Nsukka,

Print ISSN: 0331-8443, Electronic ISSN: 2467-8821

www.nijotech.com

http://dx.doi.org/10.4314/njt.v38i4.24

\title{
STRUCTURAL AND ELECTROCHEMICAL PROPERTIES OF REDUCED GRAPHENE OXIDE (RGO) SYNTHESISED USING AN IMPROVED MODIFIED HUMMERS METHOD AS ELECTRODE MATERIAL FOR ELECTRONICS APPLICATIONS
}

\author{
M. Alpha ${ }^{1,}{ }^{*}$, U. E. Uno ${ }^{2}$, K. U. Isah ${ }^{3}$ and U. Ahmadu ${ }^{4}$ \\ 1, 2, 3, 4, Dept of Physics, Federal Univ. Of TeChnology Minna, P.M.B 65, Minna, Niger State, Nigeria \\ E-mail addresses: ${ }^{1}$ alphamatthew4@gmail.com, ${ }^{2}$ uno_essang@yahoo.co.uk, \\ ${ }^{3}$ kasim309@futa.edu.ng, ${ }^{4}$ u.ahmadu@yahoo.com
}

\begin{abstract}
High quality reduced graphene oxide (RGO) nanosheets were prepared from natural graphite using an improved modified Hummers method. The morphological, structural and electrochemical properties of the RGO were characterised by scanning electron microscope (SEM), Raman spectroscopy, X-ray diffraction (XRD) analysis, Cyclic Voltammetry (CV) analysis and Electrochemical Impedance Spectroscopy (EIS) analysis. The SEM image of the RGO showed that, there was a small increase in the number of grain boundaries, indicating a collapse of the surface coalescence of the graphene oxide. The XRD peak at $24.56^{\circ}$ corresponds to the (002) diffraction plane with the interlayer spacing along the c-axis of 2.0989 A. The Raman shift for the reduced graphene oxide gives the $I_{D} / I_{G}$ intensity ratio of 1.04. The RGO exhibited good electrochemical characteristics with energy density and power density of $19.2 \mathrm{Whkg}^{-1}$ and $149.3 \mathrm{Wkg}^{-1}$ respectively.
\end{abstract}

Keywords: Reduce Graphene Oxide, Structural Properties, Morphological Properties, electrochemical properties

\section{INTRODUCTION}

Graphene oxide is an exclusive material that can be regarded as a single molecular layer of graphite with several oxygen-containing functionalities such as hydroxyl groups, carbony, carboxyl. The exceptional structure of monolayer graphite provides it with many outstanding properties such as, high quantum hall effect, amazing electronic transport properties and good chemical stability [1]. When the GO is reduced with an appropriate process, the reduced graphene oxide (RGO) formed looks like graphene but comprising residual oxygen and other heteroatoms, as well as structural defects. GO and RGO have been used in nanocomposite materials, polymer composite materials, energy storage, catalysis and as a surfacant with some overlaps between these fields. Reduce graphene oxide is one of the exciting topics in many research fields particularly in the field of nanotechnology. RGO has excellent thermal mechanical and electrical properies [2]. The general concensus is that it is very difficult to remove all the oxygen containing groups from graphene oxide. It is worth noting that the electrical performance of RGO depend on the strenght of the reducing agent. Detailed study of the structure of RGO is considered as an important step to understand the propeties of this material. Graphene, a two-dimensional (2D) nanostructure of carbon, has attracted a great deal of attention, though it was experimentally discovered in 2004 [3].

\section{EXPERIMENTAL}

The Reduced Graphene Oxide was synthesis using modified Hummer's method. In the synthesis of the reduced graphene oxide, $5 \mathrm{~g}$ of graphite, $2.5 \mathrm{~g}$ of $\mathrm{NaNO}_{3}$ and $115 \mathrm{~mL} \mathrm{H} \mathrm{SO}_{4}$, were put together and stirred for $30 \mathrm{~min}$ using a magnetic stirrer, the temperature of the mixture was controlled at approximately $5^{\circ} \mathrm{C}$. The mixture was then moved into an ice bath, then $15 \mathrm{~g} \mathrm{KMnO}_{4}$, was added slowly to mixture and maintained reaction temperature at below $20{ }^{\circ} \mathrm{C}$, after the $\mathrm{KMnO}_{4}$ was added, the temperature

* Corresponding author, tel: $+234-806-245-9364$ 
then rises to $35{ }^{\circ} \mathrm{C}$. The mixture was stirred again for another $30 \mathrm{~min}$, it became thickened and the volume increases, $230 \mathrm{~mL}$ of distilled water and ascorbic acid ( $5 \mathrm{mg}$ dispersed in $10 \mathrm{~mL}$ of water to produce a 0.5 $\mathrm{mg} \mathrm{mL}^{-1}$ ) to aid reduction was then added slowly to the mixture and reaction temperature rises to $98{ }^{\circ} \mathrm{C}$ and stirred for another $15 \mathrm{~min}$. The mixture gradually became brown. At the end of the $15 \mathrm{~min}, 400 \mathrm{~mL}$ distilled water and $50 \mathrm{~mL} \mathrm{H}_{2} \mathrm{O}_{2}$ at $30 \%$ was added to the mixture to reduce residual permanganate and manganese dioxide to colourless soluble manganese sulphate. The colour of the mixture gradually changed from dark brown to bright yellow, it was then filtered and then washed with $1 \mathrm{M} \mathrm{HCl}$ repeatedly until the $\mathrm{pH}$ value of the filtrate was close to 7 and no deposit of $\mathrm{MnSO}_{4}$ appeared in the filtrate with $\mathrm{BaCl}_{2}$ test. The sample was finally washed with $100 \mathrm{~mL}$ DI water and a cake of the reduced graphene oxide was obtained and dried in an electric oven for $60 \mathrm{~min}$.

\section{RESULTS AND DISCUSSION}

The structural properties of the RGO were analysed using the following characterisation; Phenoworld Pro
X Model Scanning Electron Microscope (SEM) operated at $2 \mathrm{kV}$ in secondary electron detection mode, high resolution Jobin-Yvon Horiba T64000-Raman Spectrometer and an XPERT-PRO X-ray Diffractometer (PANalytical, Netherlands).

\subsection{SEM Analysis}

Figure 1 shows a typical crumpled, pitted and fragmented flakes of graphene oxide stacked together forming a typical multi-layer structure of the reduced graphene oxide. The SEM image of the RGO showed that, there was a small increase in the number of grain boundaries, indicating a collapse of the surface coalescence of the graphene oxide. Individual nanosheets were visible and agglomerated layers were also noticeable, this is due to crumples in the RGO sheets and their interaction with other sheets. The heterogeneous surfaces of RGO comprising edge plane nano-bands which are exclusively the sites of electro-catalysis and therefore has a dramatic effect on the materials properties and electrochemical reactivity.

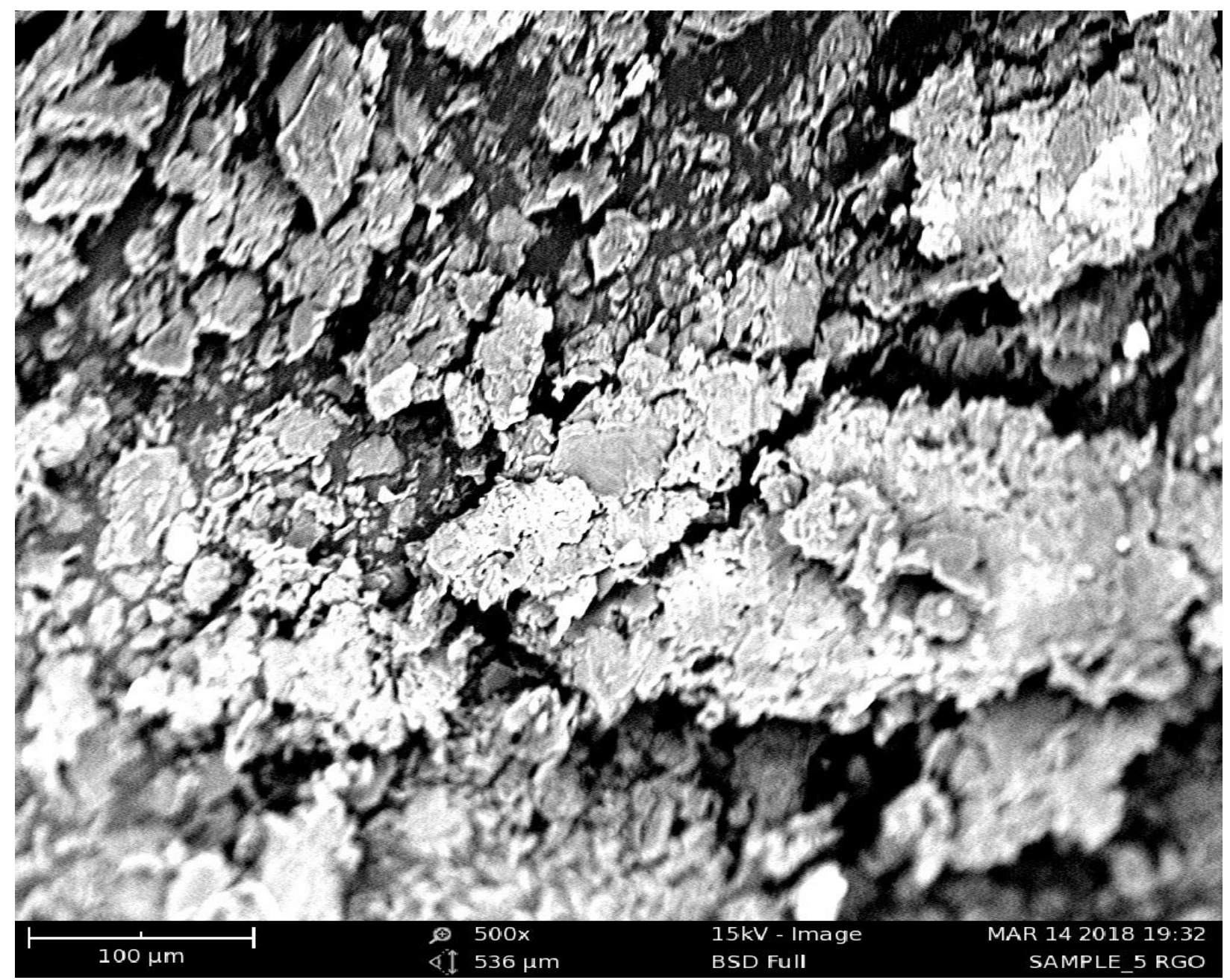

Nigerian Journal of Technology,

Vol. 38, No. 4, October 2019 
Figure 1 SEM images for RGO

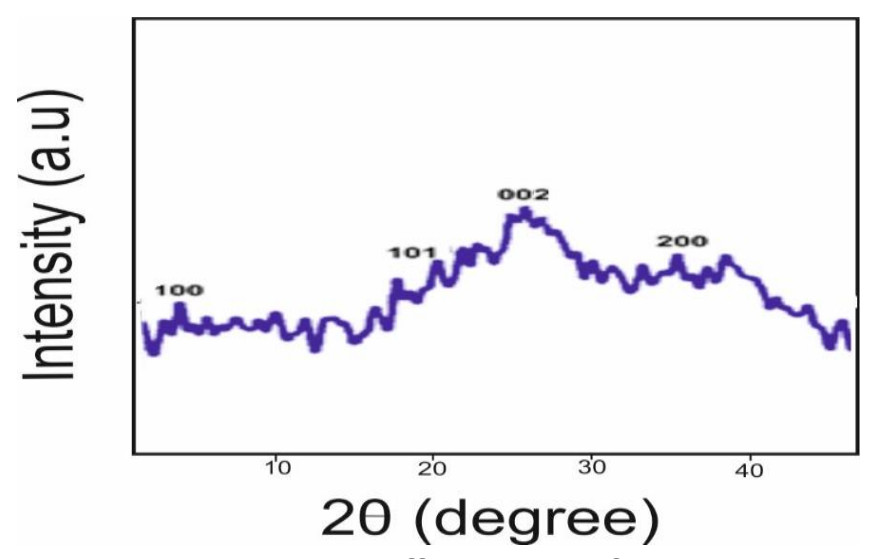

Figure 2: XRD Diffractograms for $R G O$

\subsection{XRD Analysis}

The crystal structure of the reduced graphene oxide nanocomposites was characterized by $\mathrm{X}$-ray diffraction (XRD) with CuKá1 radiation source of wavelength $1.5406 \AA$. Figure 2 shows the XRD diffractograms of the RGO, with Bragg diffraction peaks at $2 \theta$ values of $4.84^{\circ}, 20.01^{\circ}, 24.56^{\circ}$ and $33.86^{\circ}$, corresponding to (100), (101), (002) and (200) reflection planes respectively which is well indexed to the pure tetragonal rutile phase (JCPDS card no. 71-5324). The RGO peak at $24.56^{\circ}$ corresponds to the (002) diffraction plane with the interlayer spacing along the c-axis of $2.0989 \AA$. This spacing is slightly larger than that of the $d$ spacing of bulk graphite. The interlayer spacing was determined from the (002) peak by applying Bragg's law. Particle size distribution at a size of agglomeration may also be responsible for the unexpected reduction in the peak intensities. In general, the reflection planes in the reduced graphene oxide sample are in very poorly order along the stacking direction revealing that the reduced graphene oxide comprises of largely free graphene sheet but with little of insertion of interplanar oxygen group, this is in agreement with [4].

The crystallite size was calculated using Debye Scherer's equation [5].

$$
D=0.9 \lambda / \beta \operatorname{Cos} \theta
$$

Where $\lambda$ is the wavelength of CuKá1 radiation source and $\beta$ is the FWHM for the peaks. The d-spacing was calculated using Bragg's equation

$$
2 d \sin \theta=n \lambda
$$

Where $\theta$ is the Bragg's diffraction angle, $d$ is the $d$ spacing and $\mathrm{n}=1$

The microstrain was calculated using the WilliamsonHall equation [6]

$$
\beta \operatorname{Cos} \theta=2 \varepsilon \sin \theta+\frac{K \lambda}{D}
$$

Where $\beta$ is the FWHM, $\theta$ is the Bragg's diffraction angle, $\mathrm{k}=0.9, \varepsilon$ is the microstrain, $\mathrm{D}$ is the crystallite size and $\lambda$ the wavelength of CuKá1 radiation source. The dislocation density was calculated using the equation $[7,8]$

$$
\rho=\frac{1}{D^{2}}
$$

Where $\rho$ is the dislocation density and $D$ is the crystallite size.

The crystallite size is one of the most important parameter of the micro-structure of crystalline materials. It has a fundamental importance because of its macroscopic properties and technological application. Smaller crystallite size as obtained from the RGO material increases the inter-grain conduction leading to an increase in electronic conduction. Microstrain of any sample is a root mean square value and hence its value is always positive [9], the values showed that the distance of the relevant crystal planes are not indistinguishable, possibly due to the presence of defect and stress. The values of the microstrain are also ascribed to crystal imperfection, such as excess volume of grain boundaries, vacancies and vacancy clusters. The nanostructures of the RGO have small crystallite size and microstrain as a result, contributed to broadening of the XRD peaks and this is due the non-uniform displacement of atoms with respect to their reference-lattice position.

Table 1 FWHM, Crystallites size, microstrain and dislocation density for RGO

\begin{tabular}{ccccccc}
\hline $2 \theta$ (degree) & hkl & FWHM $(\beta)$ & Crystallite size $D(\AA)$ & d-spacing $(\AA)$ & Microstrain $\varepsilon$ & $\begin{array}{c}\text { Dislocation density } \rho \\
\times 10^{18}\left(/ \mathrm{m}^{2}\right)\end{array}$ \\
\hline 10.84 & 100 & 0.2952 & 5.2187 & 3.4451 & 0.0492 & 3.6717 \\
22.01 & 101 & 0.7344 & 2.1802 & 2.9752 & 0.1414 & 2.1038 \\
24.06 & 002 & 0.5904 & 3.2143 & 2.0989 & 0.1605 & 9.6789
\end{tabular}


It is worth stating that microstrain is not electronic in origin (distortion of electron shell) but it reflects an effective displacement of the atomic nuclei because lattice microstrain takes place even when static magnetic order is suppressed. The dislocation density defines the length of dislocation lines per unit volume of the crystalline material of the RGO since the formed phase is crystalline, so line defects can easily occur.

\subsection{Raman Analysis}

Figure 3 shows the Raman spectra of the reduced graphene oxide. The $\mathrm{D}$ band is the defects and disorder mode in the reduced graphene oxide, while the $\mathrm{G}$ band is the $\mathrm{sp}^{2}$-bonded vibration from carbon atoms (hexagonal lattice of graphite). The $\mathrm{G}$ and the $\mathrm{D}$ band are due to the bond stretching of all pairs of $\mathrm{sp}^{2}$ atoms and the vibrating modes of the $\mathrm{sp}^{2}$ bond [11]. The Raman shift for the reduced graphene oxide gives the $\mathrm{ID}_{\mathrm{D}} / \mathrm{I}_{\mathrm{G}}$ intensity ratio of 1.04 . From the relative high intensities of the $D$ and $G$ band, it can be resolved that the magnitude of the $\mathrm{sp}^{2}$ domains increases during the reduction of the graphene oxide. This decrease in the $G$ band intensities relative to $D$ band in the RGO discloses the disorder present in the sample.

\subsection{Electrochemical Analysis}

The electrochemical properties of the reduced graphene oxide (RGO) was analysed using Cyclic Voltammetry (CV) and the Electrochemical Impedance Spectroscopy (EIS) analysis. The cyclic voltammograms from the Cyclic Voltammetry analysis for the RGO is given in figure 4 and the Electrochemical Impedance Spectroscopy (EIS) in Figure 5.

The specific capacitance $\left(C_{\mathrm{sp}}\right)$ was calculated using the equation [12]

$$
C_{s p}=\frac{S}{2 m k(E)}
$$

Where $C_{s p}$ is the specific capacitance, $\mathrm{S}$ is the integral charge surface area of the CV curve in (mA.V), $m$ is the mass of the electrode material in $(\mathrm{g})$, $\mathrm{k}$ is the scan rate in $(\mathrm{mV} / \mathrm{s})$ and $E$ is the value of the electrode potential in $(\mathrm{V})$.
The energy density $\left(E_{D}\right)$ and power density $\left(P_{D}\right)$ were calculated using equations [13]

$$
\begin{gathered}
E_{D}=\frac{1}{8} C_{S p} V^{2} \\
P_{D}=\frac{1}{4 \times(E S R)} \frac{V^{2}}{M}
\end{gathered}
$$

The electrochemical properties of the RGO were studied using three electrode system by cyclic voltammetry (CV) and electrochemical impedance spectroscopy (EIS). The CV curve in Figures 4 gives a quasi-rectangular shape similar to report by [13].

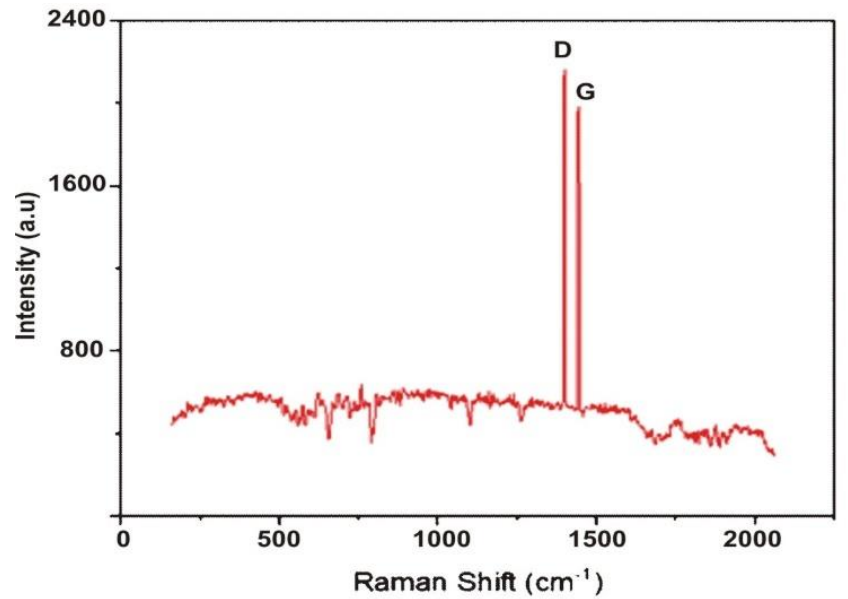

Figure 3: Raman spectra for $R G O$

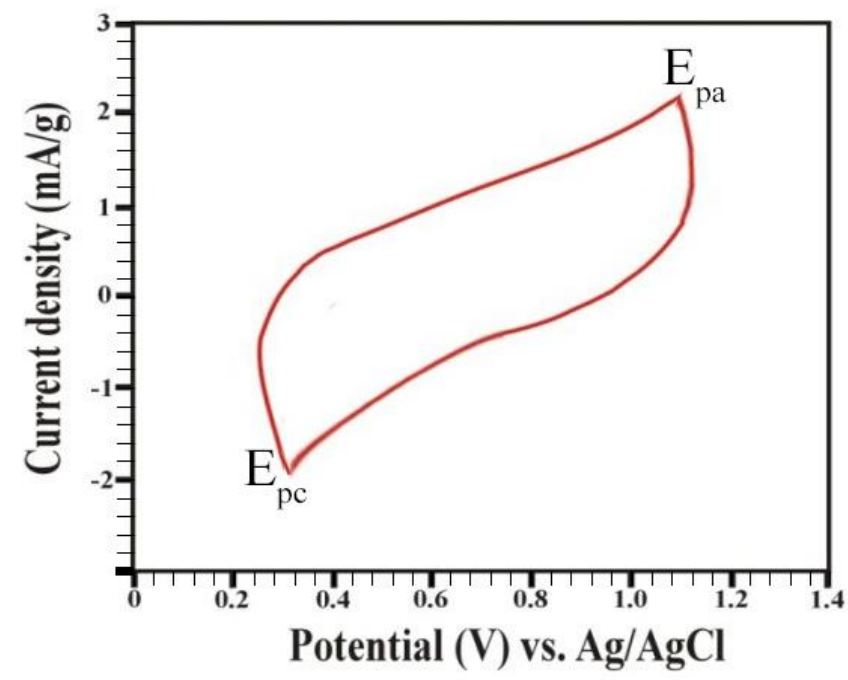

Figure 4 Electrochemical Analyses Showing Cyclic Voltammogram for the reduced grapheme oxide (RGO)

Table 2 Summary of results from electrochemical analysis

\begin{tabular}{cllllll}
\hline Sample & Mass $(\mathrm{g})$ & $\mathrm{C}_{\mathrm{sp}}(\mathrm{F} / \mathrm{g})$ & $\mathrm{ERS}(\Omega)$ & $\mathrm{E} 2-\mathrm{E} 1(\mathrm{~V})$ & $\mathrm{ED}_{\mathrm{D}}(\mathrm{Wh} / \mathrm{kg})$ & $\mathrm{PD}_{\mathrm{D}}(\mathrm{W} / \mathrm{kg})$ \\
\hline
\end{tabular}




\begin{tabular}{lllllll}
\hline RGO & 0.234 & 60.1 & 5.2 & 1.01 & 19.2 & 149.3 \\
\hline
\end{tabular}

This is due to the kinetics of electron transportation in the electrode material and the ion adsorptiondesorption at the electrode-electrolyte interface and also due to the substantial contribution of electrons in the conduction band, this is also in agreement with report by [13].

The EIS analysis is a powerful and informative technique which determines the rate that the electrode material can be charge/discharge [13], therefore an important factor in determining the power density and to evaluate the properties of conductivity and charge transport. In order to gain insight on the intrinsic electrochemical properties of the composite electrode, EIS measurement was carried within the probed frequency range of 100,000 to $0.1 \mathrm{~Hz}$.

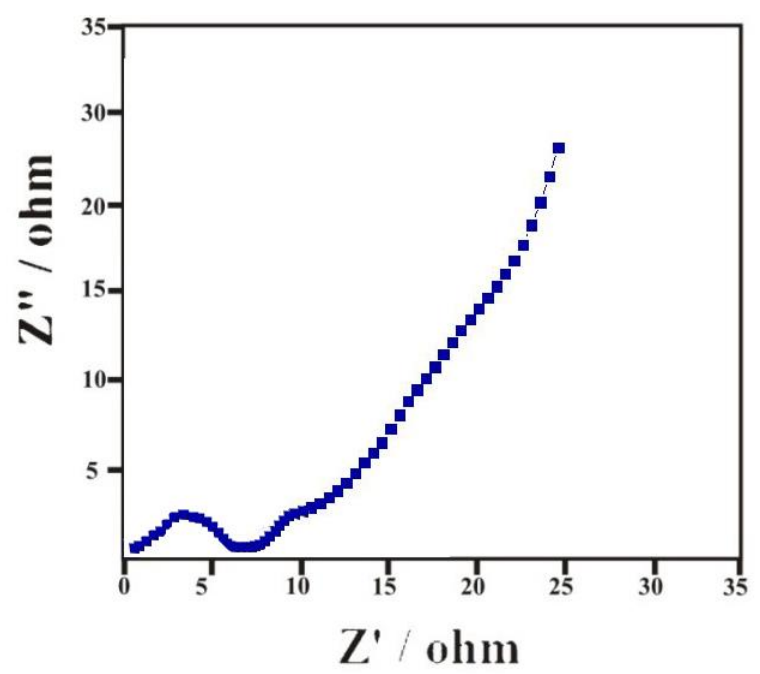

Figure 5 Electrochemical Impedance Spectroscopy Analyses Showing the Nyquist Plot for reduced grapheme oxide $(G)$

It is clearly observed from the figure 5 , that the impedance curves, which are plots of the imaginary impedance $\left(Z^{\prime \prime}\right)$ against the real impedance $\left(Z^{\prime}\right)$ consist of an arc and followed by a slanted line in the low frequency region. While in the high frequency region, the intercept of the semi-circle on the real impedance axis of the Nyquist plot represent the solution equivalent series resistance (5.2 $\Omega$ ) which can be correlated to the Ohmic resistance of the electrolyte in the system and the charge transfer resistance between interface of the electrode materials and the electrolyte as shown in Table 2 . The
Warburg impedance is related to the diffusional impedance of the electrochemical system which is employed to fit the straight line at the intermediate frequency, followed by a near vertical line at the lower frequency region as seen in Figure 5.

\section{CONCLUSION}

In summary the reduce graphene oxide (G) was synthesized using the improved modified Hummer's method. The morphological and structural properties of the RGO were studied. The SEM image of the RGO shows that, there was a small increase in the number of grain boundaries, indicating a collapse of the surface coalescence of the graphene oxide. The XRD peak at $24.56^{\circ}$ corresponds to the (002) diffraction plane with the interlayer spacing along the c-axis of 2.0989 Á. The Raman shift for the reduced graphene oxide gives the $\mathrm{I}_{\mathrm{D}} / \mathrm{I}_{\mathrm{G}}$ intensity ratio of 1.04 . The RGO gave good electrochemical properties with energy density and power density of $19.2 \mathrm{Whkg}^{-1}$ and 149.3 $\mathrm{Wkg}^{-1}$ respectively.

\section{ACKNOWLEDGEMENT}

The authors acknowledged the Technical Support of Advanced Chemistry Laboratory, Sheda Science and Technology Complex (SHESTCO) Abuja.

\section{REFERENCES}

[1] Hoai, P. P., Thanh, G. L., Quang, T. T.,Hoang H. N., Huynh, T. H., Hoang, T. T., and Tran V. C "Characterization of Ag-Doped P-Type SnO Thin Films Prepared by DC Magnetron Sputtering", Journal of Nanomaterials, 45, 2017, pp.234-337.

[2] Deng, F., Yu, L., Cheng, G., Lin, T., Sun, M., Ye, $\mathrm{F}$. , and $\mathrm{Li}, \mathrm{Y}$. "Facile synthesis of carbon nanosphere/ $\mathrm{NiCO}_{2} \mathrm{O}_{4}$ core shell", Journal of Power Source, 202, 2014, pp. 251-255,

[3] Novoselov, K.S., Geim, A.K., Morozov, S.V., Jiang, D., Zhang, Y., Dubonos, S.V., Grigorieva, I.V., and Firsov, A.A. "Electric field in atomically thin carbon film", Science, 306, 2004, pp.666-668.

[4] Frackowiak, E., and Beguin, F. "Electrochemical storage of energy in carbon nanotubes and nanostructured carbons", Carbon, 1775, 2002, pp.40-45. 
[5] Uwe, H., and Neil, G. "The Scherrer equation versus the Debye-Scherrer Equation", Nature Nanotechnology, 6, 2011, pp.53.

[6] Nakazawa, K., Itoh, S., Matsunaga, T., Matsukawa Y., Satoh, Y. and Abe, H. "Effect of dislocation and grain boundary on deformation mechanism in ultrafine-graine interstitial- free steel", Material Science and Engineering, 63, 2014, pp.012125.

[7] Lowsk, A.K., Cki, J.C., and Beker, B. "Influence of grain size on deformation mechanism: an extension to nanocrystalline materials", Dalton Ttransactions. 47, 2008, pp.6825.

[8] Alaa, A.A., and Hassanien A.S. "Micostructure and crystal imperfections of nanosized $\mathrm{CdS}_{x} \mathrm{Se}_{1-x}$ thermally evaporated thin films", Elsevier, 85, 2015, pp.67-81.

[9] Martinelli, A., Palenzona, A., Putti, M., and Ferdeghini, $C$. "Microstructural transition in 1111 Oxy-Pnictides" J.W.Lynn, Pengcheng Dai Physica, 2009, C469.
[10] Bello, A., Fabiane, M., Momodu, D.Y., Khamlich, S., Dangbegnon, J., and Manyala, N. "Functionalized graphene form as electrode for improved electrochemical storage", Journal of Solid State Electrochemistry, 18, 2014, pp.2359.

[11] Dato, A., Radmilovic, V., Lee, Z., Phillips, J., and Frenklach, M. "Substrate-Free Gas- Phase Synthesis of Graphene Sheets", Nano Letters, 8, 2008, pp.2012-2016.

[12] Yang, Q., Lu, Z., Liu, J., Lei, X., Chang, Z., Luo, $\mathrm{L}$. , and Sun, $X$. "Ultrathin $\mathrm{CO}_{3} \mathrm{O}_{4}$ nanosheet arrays with high supercapacitive performance", Progress in Natural Science Materials International, 23, 2013, pp.1-10

[13] Bello, A., Makgopa, K., Fabiane, M., DodooAhrin, D., Ozoemena, K.I and Manyala, N. "Microwave assisted synthesis of $\mathrm{MnO}_{2}$ on nickel form grapheme for electrochemical capacitor", Journal of Material Science, 114, 2013. pp. 4853 